This is an open access article under the terms of the CC-BY 3.0 License.

Peer review method: Double-Blind

Date of acceptance: July 27, 2020

Date of publication: August 14, 2020

Original scientific article

DOI https://doi.org/10.47305/JLIA2020113ob

UDC 339.9:004.8]:327

331.5:004.8]:327

\title{
TURBULENCE ON THE GLOBAL ECONOMY INFLUENCED BY ARTIFICIAL INTELLIGENCE AND FOREIGN POLICY INEFFICIENCIES
}

\author{
Kwadwo Osei Bonsu \\ Zhejiang Gongshang University, \\ School of Law and Intellectual Property, School of Economics, China \\ ORCID iD: https://orcid.org/0000-0001-5405-271X \\ k.oseibonsu@pop.zjgsu.edu.cn \\ Jie Song \\ Zhejiang Gongshang University, \\ School of Law and Intellectual Property, China \\ ralph_sj2000@zjgsu.edu.cn
}

\begin{abstract}
It is said that Data and Information are the new oil. One, who handles the data, handles the emerging future of the global economy. Complex algorithms and intelligence-based filter programs are utilized to manage, store, handle, and maneuver vast amounts of data for the fulfillment of specific purposes. This paper seeks to find the bridge between artificial intelligence and its impact on international policy implementation in the light of geopolitical influence, the global economy, and the future of labor markets. We hypothesize that the distortion in the labor markets caused by artificial intelligence can be mitigated by a collaborative international foreign policy on the deployment of $\mathrm{Al}$ in the industrial circles. We, in this paper, then proceed to propose a disposition forth essentials of Al-based foreign policy and implementation, while asking questions such as: could Al become the real 'invisible hand' discussed by economists?
\end{abstract}

Keywords: Artificial Intelligence; Foreign Policy; Invisible Hand; Global Economy; Machine Learning Algorithm; Labor Markets 


\section{INTRODUCTION}

Artificial intelligence is also known as Machine Intelligence as it is based on complex computer algorithms. It can be defined as any mechanism or phenomenon that perceives its environment and takes actions that maximize its chance of successfully achieving its goals (Poole; Mackworth and Goebel 1998). The stimulus of information is called Data. The role of the internet is growing exponentially in both governmental and non-governmental organizations. Artificial intelligence has a wide range of applicability in Governmental ministries. Al can be perceived as anon-biological form of intelligence in this era; nevertheless, there could be biologically induced $\mathrm{Al}$ in the future with advancement in quantum computing and gene editing technology. Artificial intelligence has contributed in every sphere of human life right from the home appliances to transportation by introducing self-driving cars, etc.

The application of robotics on the assembly line of many industrial complexes has also been a plus for mankind in expediting manufacturing processes. The arena of military strategies and defense forces are also enshrined with modern compact artificial intelligencebased drones that fly, combat and refill without any human effort, although there are international regulations preventing the use of autonomous weapons. Currently many military organizations along with extremist groups are using Al-based drones (Washington Post, 2017). This calls for tighter international regulation on the use of automatic weapons and the use of drones as a whole. Al will open the frontiers of human understanding at both macro and micro levels. It will enhance our rationality and help us cope with problems more effectively. Artificial intelligence also reshapes all our economic, political and social preferences; it is a powerful tool that can manipulate human behavior in most unpredicted ways. Though the development of artificial intelligence is at infancy, we cannot ignore the potentiality of threat it may pose financially, politically, economically and culturally (the extent of potential threat isn't the focus of this paper). Governments must regulate and follow up on research and development made in $\mathrm{Al}$ and respond in the best possible way to ensure maximization of utility to minimize disutility.

Artificial intelligence is widely used in both external and internal government affairs such as improved public management, urban planning, banking, security, transportation and so on. The design, building, use, and evaluation of algorithms and computational techniques is improving at an alarming rate (Desouza 2018). Data is a major entity in the era of artificial intelligence; therefore, the more data governments and public institutions manage to integrate into their systems, the higher the capabilities of machine learning to make decisions based on this data will be (Coglianese and Lehr 2018). The authenticity of data is directly proportional to the outcome of the process. This paper intends to provide the detailed effects of artificial intelligence over governments and on international policy implementation; also, to suggest an outline of solutions for the emerging complexities in foreign policy implementation with the advent of Al. Every implementation action can influence policy, 
resources, and objectives as the process evolves (McLaughlin, 1987). This paper does not intend to counter all the claims that may arise after the advent of artificial intelligence but limits its scope to matters concerned with Al and public policy and the implementation of international policy.

We in this paper used a qualitative conceptual analysis in diving into the issues surrounding artificial intelligence and foreign policy. We did cross referencing of documentation regarding both $\mathrm{Al}$, international law, international economic law, foreign policy, globalization, machine learning and sought into both the anthological and contemporary phenomena emerging in the relationship among Al, foreign policy and labor markets.

\section{ARTIFICIAL INTELLIGENCE AND GOVERNMENTS}

The development of artificial intelligence can be traced back into the XX century. In the Second World War the U.S Government was actively using artificial intelligence-based programs in marine aircrafts (Sloane 1991) though they were not as sophisticated as the modern appliances of artificial intelligence. Recent studies show that more and more human behavior can be predicated by artificial intelligence like the Google Maps suggestions of the fastest route based on data of personal Smartphone is a notable example of artificial intelligence in our daily lives. Kouziokas confers crime risk prediction as a factor that contributes to safer travel in urban areas using artificial neural networks - an example of Al (Kouziokas 2017). The algorithms will calculate high crime rate areas using local police databases; the data is organized into cluster and precisely determine the risk factor of crime in a certain area and time of a metro pole (this approach however comes with discrimination issues which will not be discussed in this paper). Birkland considers the public policy-cycle as an appropriate framework for understanding the complexity of the public decision-making processes, as well as the actors involved in such processes. Thus, activities, actors and drivers of public policy can be considered within this framework (Birkland 2015). In terms of foreign policy, artificial intelligence has opened new vistas of science and technology but many of the existing traditional diplomacy can be adapted into this new field while planning for the significant changes in the coming time. The potential of artificial intelligence to bring change in this world has initiated a competition among different governments of states to gain the strategic advantage. China's national Al strategy shows how seriously governments take this technology; China is placing major bets on the development of artificial intelligence and Robotics. Russian President Vladimir Putin stated bluntly that the country which gains an edge in Al will be the ruler of the world (The Economist 2017); this shows how heated the race among states to gain the maximum stake in $\mathrm{Al}$ is.

There are preventive measures that ought to be taken before Al fully indulges in human lives. The steps taken are discussed under the two different approaches; one is aggressive in nature while the other can be taken at a pragmatic level. Governments should 
primarily focus on assets and resources while keeping in mind the more significant planning of the near future events. The pragmatic approach of artificial intelligence does not preclude thinking about decisive changes that the technological invention might require for our foreign policy institutions. The methodology of policy making should ultimately be shaped to include a wide range of $\mathrm{Al}$ inspired applications so as to create a resonating effect on the set of opportunities and benefits that could resultantly come from artificial intelligence.

\section{AI POLICY PROPOSITIONS AND REGULATIONS}

'Lenient' policies from governments regarding the development and use of artificial intelligence would be a key factor for the growth of Al. Innovation policies should be permission less and swift if we want to capture massive breakthroughs in artificial intelligence and robotics. It is evident that the implementation of lenient policies helped spur the digital revolution in the advent of the internet. The advancement of $\mathrm{Al}$ is in a great way highly dependent on similar or even more lenient policies (Booker and Fischer 2015). Firstly, governments and policy makers must distinguish the existing areas of artificial intelligence on the basis of their utility and development techniques so that they can take the appropriate steps. For example, the regulations and preventive steps for artificial intelligence that intends to address experimental medical applications should not inadvertently be applied to social media applications of artificial intelligence because of broad or improper wording and lack of definite segregation between developmental projects.

On the other hand, some developmental programs of Al could be exempted from policy making barriers and regulations due to their utilities and sensitivities; and the kind of $\mathrm{Al}$ which may pose direct risk to public safety or health could be examined to include the kind of oversight regulations that are appropriate to minimize such risks. Secondly, governments and policy makers should figure out all the potential threats and concerns in a productive form to avoid the worst-case scenarios while deciding about the fate of the technological advancement of artificial intelligence.

Governments and policy makers have the authority and responsibility to indulge an excessive approach while engineering the rules and regulations for artificial intelligence (Atkinson 2016). Finally, the lesson of the contemporary policy approaches to the internet in the 1990s is a sufficient guidebook for the regulations of artificial intelligence. Policymakers in both of the United States and European Union follow finical models. The United States provides a clear space for experimentation and commercialization thereby inducing collaboration and growth of the internet and industry whereas the European Union appears to be inadvertently quashing the industry before it has the chance to develop making it dull in terms of utility. General openness and lenient policies towards innovation are crucial because they provide ample breathing space for the nourishment of science and technological advancement. 


\section{FOUNDATIONS OF AI-BASED FOREIGN POLICY}

Foreign policy makers and governments need to adopt a swifter approach in terms of problem solving and work ambitiously to integrate technological knowledge into our existing conventional work load fashion. It would require substantial reorganization of institutes. The pragmatic strategy is to claim the limits of the work and benchmark that was achieved in the digital era of the internet. For example: small offices might be enough to operate cyber networks but might not be sufficient to deliver the same mark of effective management and development when it comes to artificial intelligence. If we prioritize the development of artificial intelligence and new technologies, we must shift the focus or de-prioritize the other existential issues with decreasing relevance.

The second lesson for effective enforcement of artificial intelligence in foreign policy agenda is the swift and effective response of private companies, research institutes and civil societies. For that purpose, an effective knowledge of data is required to identify the most useful interventions and to overcome the effect of double occurrence by establishing a series of collaborations we draw in our existing figures. This can be illustrated from the example which Al policy issues are corresponding in terms of the arms control efforts of the cold war and the period prior to cold war (Allen \& Chan 2017).

The third lesson motivates us to adopt a problem-solving attitude while handling our foreign policy response; this actually means to avoid the bureaucratic glitches in handling specific diplomatic issues. The development of artificial intelligence is faster beyond the response rate of existing bureaucratic framework of the world as it requires conscious effort in adopting to work structures. The existing problem-solving process is axiomatic and the 'mighty' software industry that is responsible for the handling of the development of the technology of artificial intelligence and robotics and many of its features can be usefully applied in policy development.

The last lesson is that humans should be ready for the persisting challenges and difficulties which may arise during the process; these challenges can be seen to be mainly more consent with Human Resource Management. The man power skilled to work with artificial intelligence is required to meet the needs of our diplomatic practices while the conventional process of hiring and recruiting suitable candidates for the jobs in ministries of foreign affairs needs to be in tandem with the standard operations and procedure of Governments; young technology experts should be hired and involved in the crucial affairs of ministries. The challenge of finding, selecting and recruiting the artificial intelligence experts who are at the same time skilled in social science and law and then integrating them into the required posts in the required offices and embassies is not easy task. The best and the most suitable candidates for these posts may not come through the conventional mode of foreign and civil service offices and it may require a separate aptitude test of different qualities for their enrollment. 


\section{ESSENTIALS OF AI-BASED FOREIGN POLICY AND THE GLOBAL ECONOMY}

The Al's advancement has also brought about some managerial as well as social challenges in international relations. The essentials of foreign policy required for harmonious synchronization of artificial intelligence into foreign policy rules are discussed below. The first and foremost priority of foreign ministries and offices is to calculate the magnitude of the major issues that would be directly caused by the development of artificial intelligence. We cannot shape the future dilemma of artificial intelligence without setting the preferences of our research. The stakes of this technology are well understood by the nations of the states as it can be concluded from the fact that the recently published 'New Generation of Artificial Intelligence Development Plan' shows China expects to generate \$59 billion in artificial intelligence-based technology (Webster; Creemers; Triolo and Kania 2017).

The Government of South Korea initiated an investment of $\$ 863$ million in artificialintelligence technology (Nature 2016) and the many governments have allocated huge funds for the development and research of Al (Helmholtz Association 2020). This paper asserts that initiatives by the world governments is fueling the unending development of the technology under discussion and shows that policy making plays a vital role in shaping the advancement of technology in Al. However, too much attention on Al would suffocate many other areas of research which is detrimental to the development of Agriculture, Materials Science, Biology, Pharmacy etc. With diplomacy as a tool of effective communication, the media and civil societies as sources of public narrative in a society, the awareness regarding the advancement of artificial intelligence should be a major part of a new communication. The artificial intelligence has seen an acceleration of advances in the field of medicine, health, economics, finance, security and energy (Robertson 2017). These advancements were possible through Machine Learning and Data analysis obtained through the daily activities of societies (there are privacy issues which will not be discussed in this paper). Agreements are mutually consensus hence the world must engage in a productive dialogue about the future of the development of artificial intelligence since the process of dialogue will suggest new strategic challenges that would put states and international organizations onto the same page; thereby easing the strain in international relations caused by the transfer of technology. This will enhance the development of regulatory measures in governing the internet, cyber security and the digital economy. The path of development of artificial intelligence begins with the new standards of confidence building between the international policies in the groups of multilateral experts (United Nations 2016).

These series of meetings would be the foundation of international law that governs the applications of artificial intelligence. Many of the short-term and long-term agreements would be signed to minimize the impact of artificial intelligence in the labor markets because the introduction of $\mathrm{Al}$ and highly advanced robots will render a huge number of workers jobless while introducing new jobs (McKinsey Global Institute 2017). This paper disagrees with Sachs et al that both the human capital and labor workers would devalue and that only 
highly skilled artificial intelligence experts would retrieve their value (Sachs 2017). Government regulation is required to make sure a gradual integration of $\mathrm{Al}$ is executed in order to reduce the amount of turbulence caused by Al in distorting the labor markets. Foreign offices pose as the leading figures by collaborating between all the stakeholders from different regions and sectors to sort out all the challenges and build a framework to avail all the opportunities of artificial intelligence. It would be recalled that the initial conferences titled on the freedom and free use of internet resulted in strengthening the scope of the right based policy agenda. Similar agenda to promote consumer rights should be initiated. This work can be based on the footprints of public diplomacy. Introduction of a competent global body should be prioritized in advocating the narrative of global civil societies regarding the implication of the development of artificial intelligence and international policy making. The majority of the general public has had the stuff of science fiction movies in their minds regarding the implications of artificial intelligence featuring robotic killings and algorithms empowered to deliver lethal forces. In Argentina on the date of July 28, 2015, an open letter was written to the Joint conference on the development of robotics and artificial intelligence for imposing a ban on autonomous weapons (IJCAI 2015); that letter was signed by more than 3000 scientist and artificial intelligence researchers (Independent 2015). These narrative platforms also address public grievances and assist foreign bodies in policy implementation. Foreign offices and embassies should assist in integrating the available information and form a network to collaborate and share information between the different segments of their offices. Major breakthroughs in the development of artificial intelligence must be reported on priority basis and the developmental programs of artificial intelligence must be monitored. The head of the missions and project directors should be engaged with their delegations. All the opportunities and threats must be equally inspected and shared. Facial recognition and image processing where data is trained based on algorithms on the principles of information gathering (McKinsey Global Institute 2017) has been a race in China among both top and upcoming tech giants such as Baidu, Tencent, and Sensetime, etc. (Chin and Lin 2017). This is a twoedged sword, however, information sharing helps to foster cooperation thereby optimizing economic development. It can be inferred from our research that the collusion of artificial intelligence and the implementation of foreign policy is quite underdeveloped. Much research is required in artificial intelligence to develop applications usable in foreign policy implementation, whereas much research is needed in the area of international relations and international law in showing how the inevitable advancement of Al can be regulated without impeding on its progress. The significance of diplomacy and statecraft in terms of artificial intelligence is scarce because there is the lack of sufficient number of Al experts with interests and opportunities in taking key positions in foreign ministries of governments. Also, there are fewer international relations and law experts with in depth training in computer science and Al. Disparateness between technology and the social sciences causes discomfiture in implementing foreign policies relating to Al. 
This paper has discussed a brief analysis and presented guidelines on making diplomatic practices relating to artificial intelligence. As we have seen, there are institutes operating under constraints whether being political, bureaucratic, or financial constraints; this paper has given a pragmatic view of the implementation of foreign policy on artificial intelligence such as the utilization of the existing tools of diplomacy featuring fraternity of systematic adoptions. With a huge chunk of the global economy moving towards digitization, 'cyber foreign policy' should be given prime attention and discussed among both governmental and non-governmental organizations especially in the area of $\mathrm{Al}$; also, consumer right protection in digital transactions should be imperative to policy makers.

\section{CONCLUSION}

As shown in the previous chapters of this paper, advancement in Al and robotics is frustrating the usability of a portion of the labor force as well as not replacing but creating new jobs. The turbulence of this phenomenon causes distortion in the labor markets thereby shifting the supply and demand curves of labor. The global economy, geopolitics and international relations are affected dramatically as we can see; the trade war between China and the USA is partly based on the shifting of labor from the later to the former, due to the fact that most jobs in the USA, the EU and Japan have shifted from intensive labor to service based and technology based which has boosted the manufacturing sector in China. Advancement in Al has caused many factories to replace repetitive jobs in the production line with automation. Most of these factory workers have moved onto new jobs created by Uber, Didi, Meituan and many others. While others are video streaming and selling products on Tiktok. These are examples that show that new jobs are created whiles others are being lost. During the industrial revolution, horse groomers probably were worried about losing their jobs while new jobs like mechanics were being created. It is a 'hand-go-hand-come' tale. Artificial intelligence could create a new political revolution where everything is governed by itself through a real 'invisible hand'. It could (if not become) perform the actions of the invisible hand which economists have theorized for decades. Lenient policies from governments regarding the development and use of artificial intelligence would be a key factor for the growth of Al. Also, governments and educational institutions should come up with programs that train a breed of technology, Al, law, international relations and economics hybrids of experts to be given key policymaking roles in multi-national endeavors. 


\section{REFERENCES}

1. Appendix in Allen, G. \& Chan, T., 2017. Artificial Intelligence and National Security. Belfer Center for Science and International Affairs Harvard Kennedy School. Cambridge

2. Cary Coglianese and David Lehr. 2016. Regulating by robot: Administrative decision making in the machine learning era. Geo. LJ 105(2016), 1147.

3. Chin, J. \& Lin, L., 2017. China's All-Seeing Surveillance State Is Reading Its Citizens' Faces. The Wall Street Journal.

4. Cory Booker (D-NJ) and Deb Fischer (R-NE), Adam Thierer, "What Cory Booker Gets about Innovation Policy," Technology Liberation Front, February 16, 2015. September 25, 2015.

5. Georgios N Kouziokas. 2017. The application of artificial intelligence in public administration for forecasting high crime risk transportation areas in urban environment. Transportation research procedia 24 (2017), 467-473.

6. German Research Center for Artificial Intelligence (DFKI), the relevant Fraunhofer Institutes, the Helmholtz Association of German Research Centres. 2020, accessed June 15, 2020 , https://www.dfki.de/en/web/news/detail/News/more-space-forartificial-intelligence-dfki-bremen-starts-construction-on-extension-with-new-test-s/

7. Independent.2015, accessed June 15, 2020, https://www.independent.co.uk/lifestyle/gadgets-and-tech/news/stephen-hawking-elon-musk-and-others-call-forresearch-to-avoid-dangers-of-artificial-intelligence-9972660.html

8. Kevin Desouza. 2018. Delivering Artificial Intelligence in Government: Challenges and Opportunities. "IBM" center for the Business of Government (2018).

9. McKinsey Global Institute, 2017. A Future that Works: Automation, Employment, and Productivity. McKinsey Global Institute

10. McKinsey Global Institute, 2017. Artificial Intelligence. The next Digital Frontier? McKinsey Global Institute. Over the last 2.5 years, Baidu has invested \$1.5 billion in Al research

11. McLaughlin, M.W. Learning From Experience: Lessons From Policy Implementation. Educ. Eval. Policy Anal. 1987, 9, 171-178

12. Nature. 2016, accessed June 11, 2020, https://www.nature.com/news/south-koreatrumpets-860-million-ai-fund-after-alphago-shock-1.19595

13. Open Letter on Autonomous Weapons. International Joint Conference on Artificial Intelligence (IJCAI) 2015

14. Poole, Mackworth\& Goebel 1998. Computational Intelligence.

15. Robert D. Atkinson, "It's Going to Kill Us", 2016 https://files.eric.ed.gov/fulltext/EJ1121424.pdf

16. Robertson, S. K., 2017. How Google Brain is making major advancements in machine learning. The Globe and Mail. 
17. Sachs, J., 2017. Robotics, Al, and the Macro-Economy

18. Stephen B Sloane. 1991. The use of artificial intelligence by the United States Navy: Case study of a failure. Al Magazine 12, 1 (1991), 80-80.

19. The Economist. 2017, accessed June 102020 https://www.economist.com/news/leaders/21721656-data-economy-demands-newapproach-antitrust-rules-worlds-most-valuable-resource

20. Thomas A Birkland. 2015. An introduction to the policy process: Theories, concepts, and models of public policy making. Routledge

21. United Nations Geneva. 2016, accessed June 15, 2020, https://www.unog.ch/80256EE600585943/(httpPages)/8FA3C2562A60FF81C1257CE60 0393DF6?OpenDocument

22. Washington Post. 2017, accessed June 10, 2020, https://www.washingtonpost.com/world/national-security/use-of-weaponizeddrones-by-isis-spurs-terrorism-fears/2017/02/21/9d83d51e-f382-11e6-8d72263470bf0401 story.html

23. Webster, G., Creemers, R., Triolo, P., Kania, E., 2017. China's Plan to 'Lead' in Al: Purpose, Prospects, and Problems. See China's "China Manufacturing 2025" plan. 